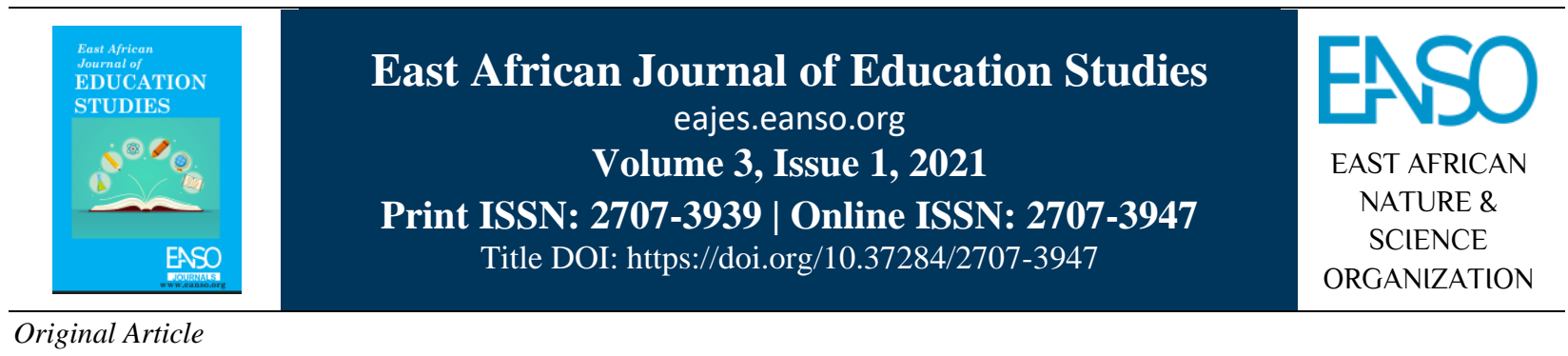

\title{
Challenges of Teaching and Assessing the 21st-Century Competencies in Africa: A focus on the Kenyan New Curriculum of Basic Education
}

\author{
Ruth Nanjekho Wafubwal \\ ${ }^{1}$ University of Szeged, H-6720 Szeged, Dugonics square 13, Hungary. \\ * ORCID: https://orcid.org/0000-0002-7236-8408; Author for Correspondence Email: ruthnanje@ gmail.com.
}

Article DOI: https://doi.org/10.37284/eajes.3.1.332

\section{Date Published: ABSTRACT}

24 May 2021 The ever-changing demands of modern life have seen education policymakers worldwide come up with ways of incorporating 21 st-century competencies in

Keywords: education systems. Many countries in the world have incorporated these competencies in their education systems though some are still faced with

Competency-Based

Curriculum,

Basic Education,

Assessment,

Implementation

Challenges. challenges. With a special focus on Kenya, this paper addressed the challenges that African countries have faced in the process of implementing and assessing 21 st-century competencies in basic education. A comparison of the Kenyan and Finnish basic education assessment frameworks was done to find out what Kenyan education policymakers can learn from the Finnish curriculum. The findings of the study showed that the Kenyan assessment framework is too sketchy and cannot give clear guidance to teachers. There was also a lack of an assessment culture that could enable teachers to effectively carry out formative assessment practices. The study recommends the need for curriculum developers to provide a clear and elaborate assessment framework for teachers, train teachers on formative assessment use, and provide teachers with an effective support system. This study is not only beneficial to Kenyan education policymakers but other African countries especially those implementing the competency-based curriculum.

\section{APA CITATION}

Wafubwa, R. N. (2021). Challenges of Teaching and Assessing the 21st-Century Competencies in Africa: A focus on the Kenyan New Curriculum of Basic Education. East African Journal of Education Studies, 3(1), 96-105. https://doi.org/10.37284/eajes.3.1.332.

\section{CHICAGO CITATION}

Wafubwa, Ruth Nanjekho. 2021. "Challenges of Teaching and Assessing the 21st-Century Competencies in Africa: A focus on the Kenyan New Curriculum of Basic Education". East African Journal of Education Studies 3 (1), 96-105. https://doi.org/10.37284/eajes.3.1.332.

96| This work is licensed under a Creative Commons Attribution 4.0 International License. 


\section{HARVARD CITATION}

Wafubwa, R. N. (2021) "Challenges of Teaching and Assessing the 21st-Century Competencies in Africa : A focus on the Kenyan New Curriculum of Basic Education", East African Journal of Education Studies, 3(1), pp. 96-105. doi: 10.37284/eajes.3.1.332.

\section{IEEE CITATION}

R. N. Wafubwa, "Challenges of Teaching and Assessing the 21st-Century Competencies in Africa: A focus on the Kenyan New Curriculum of Basic Education”, EAJES, vol. 3, no. 1, pp. 96-105, May. 2021.

\section{MLA CITATION}

Wafubwa, Ruth Nanjekho. "Challenges of Teaching and Assessing the 21st-Century Competencies in Africa: A focus on the Kenyan New Curriculum of Basic Education”. East African Journal of Education Studies, Vol. 3, no. 1, May. 2021, pp. 96-105, doi:10.37284/eajes.3.1.332.

\section{INTRODUCTION}

The past two decades have been a wake-up call for educational policymakers worldwide to review how best education systems could prepare young people in handling the demands of modern working life (Halpern, 2008). This resulted in countries coming up with different models of competencies and skills generally referred to as $21^{\text {st }}$-century competencies. Although different organizations developed their models, the competencies of interest were transversal and multidimensional (Voogt \& Roblin, 2012).

Different approaches were used in addressing the transversal competencies in the educational context. The Organization for Economic Co-operation and Development (OECD) launched the first model in the late 1990s which was known as "Definition and Selection of Competencies (DeSeCo)". The main aim of DeSeCo was to define competencies for a successful life and well-functioning society and clarify the concept of competencies (Rychen \& Salganik, 2003). Alongside the DeSeCo project, two programs on the future of PISA assessment by OECD and the key competencies of the European Union (EU) were born in the late 1990s. Based on research and recommendations by the European parliament, competencies were defined as a combination of knowledge, skills, and attitudes appropriate to the context and key competencies as competencies necessary for personal fulfilment and development, active citizenship, social inclusion and employment (Crick, 2008; Halász \& Michel, 2011). The European framework on competencies considered learning to learn as a very important competency that supports all other learning activities. Learning to learn project was therefore launched to develop European assessment tools that were piloted in eight countries in 2008 (Kupiainen et al., 2008).

The Partnership for $21^{\text {st }}$ Century Learning (P21) model which was founded in 2002 suggested themes on global awareness; financial, economic and entrepreneurial literacy; civic literacy; health literacy and environmental literacy to be included in the traditional school subjects. Assessment and teaching of $21^{\text {st }}$-century skills (ATC21S) model identified four dimensions of Knowledge; Skills; and Attitudes/Values/Ethics which were referred to as the KSAVE model. The National Research Council project in the United States of America categorized the types of knowledge and skills students need for college and career as Cognitive skills; Interpersonal skills and Intrapersonal skills (Pellegrino \& Hilton, 2012).

Two approaches were used to come up with core competencies. Lai and Viering (2012) compared the $\mathrm{P} 21$, the ATC21S, and the National Research Council projects which resulted in five important common constructs as critical thinking, creativity, metacognition, collaboration, and motivation. The second approach by Voogt and Roblin (2012) involved a systematic analysis of eight frameworks which included: P21; ATC21S; OECD DeSeCo; the New Millennium Learners project; and the EU key competencies. The focus was on skills and competencies, implementation, and assessment. Although some competencies seemed to be overlapping, key competencies were mentioned in all frameworks.

The ATC21S had a stronger emphasis on the assessment of four broad categories of skills which included: ways of thinking, ways of working tools,

97| This work is licensed under a Creative Commons Attribution 4.0 International License. 
tools of working, and living in the world (Lai \& Viering, 2012; Care et al., 2018). The greatest task has been on measuring the core competencies (Care $\&$ Griffin, 2017). Some of the assessment tools that have been suggested for assessing the competencies include the use of self-reports, Global rating scales, standardized assessment, and observational measures (Lai \& Viering, 2012).

\section{Core Competencies and Assessment in Kenyan Basic Education}

Kenya is one of the countries that have adopted the framework for implementing $21^{\text {st }}$-century competencies. The new Competency-Based Curriculum (CBC) is seen as the means through which the skills and knowledge needed for the economic growth and development in the country will be realized (KICD, 2017). The CBC is a learner-centred pedagogy that focuses on the learner's application of the skills learned to solve the day-to-day challenges. According to KICD (2017), competence is defined as "the ability to apply appropriate knowledge and skills to successfully perform a function". In the Kenyan context, every learner is expected to achieve seven core competencies which have been described as "Communication and Collaboration; Self-efficacy; Critical Thinking and Problem Solving; Creativity and Imagination; Citizenship; Digital Literacy; and Learning to Learn" (KICD, 2017 p.21).

Competence-Based Assessment (CBA) in the Kenyan context is described as "determining the capability to apply a set of related knowledge, skills and abilities required to successfully perform critical work functions or tasks in a defined setting" (KICD, 2017 p. 114). The assessment of competencies is expected to be achieved through a formative assessment which is deemed to enhance learning and learning outcomes. The implication is that teachers need a paradigm shift from the traditional teacher-centred assessment to student centred assessment approaches. Formative assessment is carried out by teachers and students as part of the day-to-day activity (Clark, 2012). Studies have suggested that formative assessment has got a lot of benefits if well implemented (Black \& Wiliam, 2009; Wiliam, 2011). Some of the benefits include: empowering students to learn how to learn (Swaffield, 2011), and making learning visible
(Black \& Wiliam, 2009; Demetriou et al., 2011; Csíkos et al., 2011). Formative assessment is thus integral to the teaching-learning process and acquisition of competencies (Voogt \& Roblin, 2012; Pepper, 2011).

This paper aims to reflect on the $\mathrm{CBC}$ implementation challenges encountered by African countries. Specifically, the paper focuses on the challenges encountered by Kenyan primary school teachers during the implementation of $\mathrm{CBC}$ and suggests remedies.

\section{Competence-Based Curriculum in Africa: Implementation Challenges}

A framework for curricular integration of the 21stcentury competencies distinguishes between the intended; the implemented, and the attained curriculum. As described by Voogt and Roblin ( 2012), the intended curriculum encompasses the 21 st-century competencies needed in the knowledge society. The competencies addressed in the national and the school curricula form part of the implemented curriculum. The attained curriculum is the outcome of the implemented curriculum which should be measured through appropriate assessment practices. Studies have shown that $21^{\text {st }}$-century competencies have been introduced in the curriculum policies and regulations under various terminologies and most of them have been integrated across the curriculum (Ananiadou \& Claro, 2009; Voogt \& Roblin, 2012).

The introduction of a competency-based curriculum in African basic education has been one of the highly ambitious curriculum reforms spearheaded by international agencies such as the World Bank, UNICEF, and UNESCO. The CBC has been implemented in most African countries as a global response to the aligning of the curriculum to $21^{\text {st }}$ century skills. The CBC in Kenya was piloted in 2017 July and then implemented in the whole country in January 2019 amid cries of dissatisfaction from the public (Wanzala, 2018). In Cameroon, the competence-based approach was introduced in 2012 and 2013 (Esongo, 2017); Rwanda in 2015 (Ndihokubwayo \& Habiyaremye, 2018); Senegal in 2005 (Gauthier, 2013); Tanzania

98| This work is licensed under a Creative Commons Attribution 4.0 International License. 
in 2005 (Komba \& Mwandaji, 2005); Zambia in 2013 (Nambela, 2016).

Studies assessing the impact of $\mathrm{CBC}$ on student achievement in some of these countries show that CBC has not impacted positively students' achievement. For instance, the findings from a review by Gauthier (2013) on the CBC implementation in five African countries (Cameroon, Gabon, Mali, Senegal, and Tunisia) revealed that the curriculum reforms have not yielded any improvement in students' outcomes. Gauthier (2013) attributed the failure of the CBC to issues such as poorly designed try-out phase, introducing $\mathrm{CBC}$ reforms alongside other reforms, lack of clarity in the concept of $\mathrm{CBC}$, lack of clear procedures in providing guidance, inadequate teacher preparation, taking lightly the social changes resulting from the reforms, a mismatch between learning and assessment, and inadequate budgetary management.

Studies on the implementation of CBC in Tanzania have shown that the implementation was ineffective and has not resulted in any positive students' achievements (Komba \& Mwandaji, 2016; Makunja, 2016; Lukindo, 2016). According to Paulo (2014), pre-service teachers are not always prepared to apply the $\mathrm{CBC}$ in schools after their training. Similar observations were made by Makunja (2016). These studies have pointed to specific areas of concern as inadequate teacher preparation, lack of enough teaching and learning resources, overcrowded classrooms, low ability of students who join secondary schools, and lack of students' readiness to accept learner-centred approaches.

In Rwanda, CBC was introduced in 2015 and challenges faced relate mainly to the textbook content. Teachers complained about too much content which hinders timely syllabus completion (Ndihokubwayo \& Habiyaremye, 2018; Kizito et al., 2019).

The CBC was introduced in Zambia in 2013 and currently, it is being used at all levels of basic education. Research on its effectiveness attests to the fact that the implementation process was hurriedly done and teachers were neither adequately prepared nor involved in the development process
(Nambela, 2016; Mulenga \& Kabombwe, 2019). The Zambian teachers also complained about the textbook content which was either too shallow or too loaded (Musilekwa \& Mulenga (2019).

\section{The CBC Implementation Challenges in Kenya}

Before the implementation of the CBC curriculum in Kenya, a pilot study was conducted in some selected schools in the year 2017. The first pilot study was conducted for the Pre-Primary 1 and 2 (PP1 and PP2, ages 4-5) and Primary 1 and 2 (ages 6-7) in 450 primary schools across the country. An external report on the pilot implementation by IBEUNESCO (2017) revealed that the implementation was impressive but still teachers encountered some challenges. These challenges are mainly related to the assessment of the learners. The $\mathrm{CBC}$ curriculum requires teachers to use formative assessment in the course of their teaching which proved to be a challenge for most teachers. Teachers who were interviewed cited various challenges.

As reported in the external evaluation report (IBEUNESCO, 2017), the first challenge was a mismatch between the curriculum 'designs book' and the learners 'workb ook'. As a result of the mismatch, more than $50 \%$ of the teachers experienced difficulties in identifying the right assessment procedures for the content. Related to this problem was the lack of clear timeframes for different topics hence teachers could not figure out how long each topic should take. The second challenge according to the IBE-UNESCO report was the time taken to prepare for lessons. All teachers who were interviewed raised concerns of too much time that was taken in lesson preparation which ended up compromising the essence of contextualizing the learning materials. Teachers needed time to figure out the appropriate type of learning resources since most of the resources suggested in the design books were out of reach. For example, the design book could require learners to use resources such as a swimming pool, or video games that could not be easily accessed. The third concern was about insufficient numbers of learners' workbooks forcing learners to share amongst themselves (IBE-UNESCO, 2017).

Apart from the books being insufficient, they were either challenging or too shallow. Some teachers

99| This work is licensed under a Creative Commons Attribution 4.0 International License. 
also mentioned the parents' concern relating to the assessment of learners' progress. The assessment framework proposed by KICD (2018) suggested a checklist to be followed by teachers in monitoring the learners' progress. Teachers were not however supplied with a template that would guide them. The difference in learning ability was another concern expressed by the teachers since higher achieving learners were able to finish the tasks faster than the low achievers. As a result of individual differences in task performance, teachers had challenges in creating a balance between extreme cases. Some PP1 teachers felt that the 30 minutes duration for the class period was not sufficient for the lesson activities. Another concern was content materials not suiting the learners' ability, or their learning progression. Teachers also felt there was no opportunity to integrate technology in teaching since the laptops were only provided to one public school. Parents were mainly worried about the assessment procedures that will inform them of their children's academic progress (IBE-UNESCO, 2017).

The observations of teachers' preparation for teaching and assessment by IBE-UNESCO revealed that teachers simply copied the phrases directly from the design books with signs of miscomprehension. Teachers attempted to develop the assessment instruments but the performance levels did not match the assessment rubrics in the design books. The evaluation team recommended the need to elucidate the use of formative assessment by the teachers. There was a need to equip teachers with skills of how to keep assessment records and communicating the results to parents and students. The team also recommended a reexamination of the instruction materials and assessment procedures before a final rollout to the entire country. Similar recommendations were raised by KICD (2018) and Sossion (2017). Comments on the implementation of the CBC in the daily nation newspaper by Wanzala (2018) indicated that parents were not fully aware of what CBC is all about and only 20 percent of teachers were adequately prepared for the curriculum rollout.

\section{What is Missing in the Kenyan Competency- Based Assessment (CBA) Framework?}

The Kenyan Basic Education Curriculum Framework (KBECF) has been portrayed as "the outcome of extensive stakeholder engagement, a national needs assessment study, deliberations from a national curriculum reform conference and several benchmarking studies" (KICD, 2017. P3). One wonders why a well-planned curriculum reform still had so many flaws during the implementation phase, some of which were never addressed before the national rollout.

A critical look at the assessment framework chapter justifies the concerns of teachers and parents. The chapter emphasizes formative assessment as an approach to assessing competencies and outlines some of the assessment instruments such as observation, checklists, and journaling among others (KICD, 2017, p. 113-128). Out of more than 10 assessment instruments outlined, only three have been briefly illustrated. The mismatch between the curriculum 'design book' and learners' 'workbook' could have been due to a lack of clarity in assessment instruments. Learner's grade to grade progress is also not defined. It's not clear what will happen to the learners who will not meet the minimum requirements of the assessed competencies. If the current policy where no learner is supposed to repeat a class is retained under the $\mathrm{CBC}$ then the essence of competency development will be meaningless because learners will not be kept on track. From the pilot report, teachers had difficulties attending to learner's differences since learners finished the tasks at different times which challenged the teacher's time management.

According to the assessment framework, the formulation of the final grade will be based on the cumulative formative assessment scores and the final summative score from the national assessment body. The framework does not, however, give precise information on the management of the cumulative scores. If the IBE-UNESCO (2017) report revealed that teachers were already overwhelmed during lesson preparation, it can only be imagined how overwhelming teachers will be in keeping the formative assessment reports for all the stages. The Kenyan CBA framework is generally

100| This work is licensed under a Creative Commons Attribution 4.0 International License. 
sketchy focusing more on definitions of terms at the expense of dealing with practical issues.

\section{LESSONS FROM SUCCESSFUL COUNTRIES: A CASE OF FINLAND}

The concerns expressed by teachers and parents during the try-out phase point to the fact that the $\mathrm{CBC}$ is alien in Kenya. As discussed earlier, the African countries which have tried to implement the $\mathrm{CBC}$ all failed at the implementation stage. The strong influence of foreign experts from countries like Malaysia, Canada, New Zealand, and the Netherlands may have influenced the Kenyan education policymakers in adopting a curriculum that best suits the developed countries. Unfortunately, the Kenyan policymakers seemed not to have learned much from the challenges experienced by other African countries like Tanzania which had already implemented the curriculum but chose to benchmark with the developed countries. Worse enough, the competencies were not interpreted in the African context but were instead taken as they were described in international frameworks for $21^{\text {st }}$ century skills. Few western countries have successfully incorporated the competencies in basic education. A case in point is Finland whose education system has been celebrated as a $21^{\text {st }}$ century global success story and has been a benchmark to most countries in Europe and across the world (Takayama et al., 2013).

Just like the Kenyan education system, the Finnish education system has gone through several reforms and these reforms have not been without challenges (Vainikainen, 2014; Vainikainen et al., 2017). The current Finnish core curriculum for basic education which was established in 2014 has not been fully implemented in all the grades. The implementation has been gradual since 2016 and the current ninth graders are still following the old curriculum. The Kenyan basic education curriculum has similarly gone through several reforms. The current 8:4:4 system of education is being phased out and the new CBC has already been implemented in lower primary schools (grades 1 to 4) and the implementation is hoped to gradually take place until it is fully implemented at all levels of basic education (KICD, 2017). Both the Finnish and Kenyan Basic Education Curriculum Frameworks appreciate the role of student assessment in enhancing the students' learning (Finnish National Board of Education, 2016; KICD, 2017).

\section{Comparing the Finnish and Kenyan Basic Education Assessment Frameworks}

The analysis of the Finnish and Kenyan assessment framework revealed several similarities and differences. Both frameworks stress the use of formative assessment in assessing competencies. The object of assessment is the same for both countries in that both countries assess learners holistically.

Three major differences emerged in the two assessment frameworks. First, the assessment culture is quite strongly expressed in the Finnish curriculum but less stressed in the Kenyan framework. The teachers, guardians, and the local authority play an important role in ensuring an assessment culture that promotes peer and selfassessment skills in the learners. The strong assessment culture has motivated teachers in assessing the pupils without supervision. The strong assessment culture is enhanced by highly qualified teachers who are free to exercise their expertise (Vainikainen, et al., 2017). On the contrary, there is a lack of a supportive assessment culture in Kenya. Too much stress on high stake examination and teachers' accountability has limited the use of formative assessment by Kenyan teachers (Ngware et al., 2014). There is yet a lot to be done to develop an assessment culture that will ensure teacher autonomy and trustworthiness. Maybe embracing a local curriculum in addition to the national core curriculum can help in ensuring a supportive environment for both teachers and Learners.

The second difference relates to the assessment of progress in basic education. In Finnish basic education, assessment of progress is either based on the grade to grade or according to a personal study plan. The prerequisite for grade to grade progress is that the learner must meet the minimum requirements as stipulated in the framework. The Kenyan framework does not specify how learners will progress from one grade to the next. Currently, the policy on student promotion to the next class is that no student should be compelled to repeat a class. There is a need for the curriculum developers

101| This work is licensed under a Creative Commons Attribution 4.0 International License. 
to specify how learners will progress from one grade to the next.

The third major difference regards the awarding of the final grade. In Finland, grades are given based on the achievement level that the pupil demonstrates at the end of the studies but not as an average of the grades in the pupil's reports for previous courses. The challenge that is likely to arise in the Kenyan case is the management of cumulative scores for the different levels before the final summative assessment. This will turn out to be cumbersome to teachers because they will be involved too much in record-keeping at the expense of classroom instruction. It would be better if the assessment of progress be done the way it is done in Finland so that the teacher's workload is minimized.

\section{How the Implementation Challenges have been handled in Finland}

In handling challenges of individual differences, the Finnish curriculum allows differentiation of teaching which is central to every teacher's daily job. This is however done with the help of other professional staff like doctors, special education teachers, and psychologists. Differentiation teaching is based on individually formulated smallscale learning goals, adapted materials, flexible learning time, and different learning approaches. Although general goals are specified in the curriculum, they can be achieved at different levels and teachers are allowed to emphasize only the relevant contents. The pupils and their parents are expected to be made aware of the goals and how they are reached. The goals for teaching content and behaviour are broken down into the period, week, lesson, and individual task. Remedial instruction is organized as an extra lesson for pupils who may have been absent from school due to sickness and for challenging topics.

Flexibility in the organization of teaching in Finland has helped in reducing teachers' workload. This involves adjusting working methods according to pupils' needs. For instance, regulating group sizes such that some subjects are taught in larger groups whereas more resources are allocated in teaching basic competencies in smaller groups; teachers collaborate by merging smaller groups and teaching them at the same time while others work independently or disciplinary borders can be crossed and work can focus on aspects from different perspectives.

The great support system in Finnish basic education has helped in the effective implementation of the core competencies. Special education is part of a support system for everyone and it's undertaken through co-teaching, screening and consulting, preparing individual materials, provision of parttime special education as co-teaching or in small groups.

Student assessment is jointly done where teachers do systematic observations through co-teaching; screening, discussing, and documenting. The Finnish curriculum emphasizes the importance of multiple ways of demonstrating competencies. Assessment is also done through self and peer assessment. Feedback is encouraged where pupils are informed on the progress, on where the gaps still are, and on what they should do to close the gap. Formulation of the pupil's final grade is based on the achievement level that the pupil demonstrates at the end of the studies in proportion to syllabus objectives and the final assessment criteria but not on average grade from the previous performance.

\section{SUMMARY, CONCLUSIONS, AND RECOMMENDATIONS}

This paper aimed to reflect on the challenges encountered during the implementation of a competency-based curriculum in African countries with a special focus on Kenya. By comparing the competency-based assessment frameworks of Kenya and Finland, it was realized that there are some issues of concern in the Kenyan CBA framework that have not been spelled out, and hence the curriculum developers need to review and make a conclusive assessment framework. Since the implementation of CBC is still in its early stage, the developers still have an opportunity to address the challenges so that curriculum implementation becomes practical. It's a fact that what works in one culture may not necessarily work in a different culture. Comparing the Kenyan student assessment framework with the Finnish one does not mean that we copy and paste the Finnish curriculum but what is of importance is that we borrow and apply what is workable in the Kenyan context.

102 This work is licensed under a Creative Commons Attribution 4.0 International License. 
Some of the aspects that could be borrowed include: equipping teachers on how to carry out the formative assessment; providing the support system to both teachers and students, matching the curriculum goals with the competencies; providing for differentiation of learning so that learners can learn at their own pace; clarifying the criteria on how learners can progress from one grade to the next and basing the final assessment on the achievement level that the learner demonstrates at that particular time instead of using the average of formative assessment at different stages. The greatest focus should be on developing an elaborative assessment and evaluation system for the competencies.

\section{REFERENCES}

Ananiadou, K. \& Claro, M. (2009). 21st Century Skills and Competences for New Millennium Learners in OECD Countries. OECD Education Working Papers, No. 41. OECD Publishing.

Black, P., \& Wiliam, D. (2009). Developing the theory of formative assessment. Educational Assessment, Evaluation and Accountability (formerly: Journal of Personnel Evaluation in Education), 21(1), 5-31.

Care, E., \& Griffin, J. A. (2017). Assessment of collaborative problem-solving processes The Nature of Problem Solving: Using Research to Inspire 21st Century Learning. Paris: OECD Publishing.

Care, E., Griffin, P., \& Wilson, M. (Eds.). (2018). Assessment and Teaching of 21 st Century

Skills: Research and Applications. Cham, Switzerland: Springer International Publishing.

Clark, I. (2012). Formative assessment: assessment is for self-regulated learning. Educ Psycho Rev $24,205-249$.

Crick, R. D. (2008). Key Competencies for Education in a European Context: narratives of accountability or care. European Educational Research Journal, 7(3), 311-318.
Csíkos, C., Szitányi, J., \& Kelemen, R. (2012). The Effects of Using Drawings in Developing Young Children's Mathematical Word Problem Solving: A Design Experiment with Third-Grade Hungarian Students. Educational Studies in Mathematics, 81 (1), 47-65.

Demetriou, A., Spanoudis, G., \& Mouyi, A. (2011). Educating the developing mind: Towards an overarching paradigm. Educational Psychology Review, 23 (4), 601-663.

Halász, G., \& Michel, A. (2011). Key Competences in Europe: interpretation, policy formulation, and implementation. European Journal of Education, 46(3), 289-306.

Halpern, D. F. (2008). Is intelligence critical thinking? Why we need a new definition of intelligence. In Kyllonen, P. C., Roberts, R. D., \& Stankov, L. (Eds.), Extending Intelligence. Enhancement and New Constructs (pp. 293310). New York: Routledge.

Esongo, N. M. (2017). Correlation between the Availability of Resources and Efficiency of the School System within the Framework of the Implementation of Competency-Based Teaching Approaches in Cameroon. Journal of Education and Practice, 8(2), 82-92.

Finnish National Board of Education. (2016). National Core Curriculum for Basic Education 2014. Helsinki, Finland: Finnish National Board of Education.

Gauthier, R.F (2013). A competency-based approach to curriculum reform in five African Countries: What can we learn from the 20082009 evaluation? Prospects, 43 (4), 429-439.

IBE-UNESCO (2017). The why what and how of the competency-based curriculum reforms: The Kenyan Experience. Geneva.

Kenya Institute of Curriculum Development (KICD). 2017. Republic of Kenya: Basic Education Curriculum Framework. Republic of Kenya, KICD.

Kenya Institute of Curriculum Development (KICD), 2018. Report on the Competency-Based

103 This work is licensed under a Creative Commons Attribution 4.0 International License. 
Curriculum activities presented to the National Steering Committee. Nairobi: KICD

Kizito, N., Telesphore, H. H., \& Rukundo, J. C. (2019). Rwandan New Competence Base: Curriculum Implementation and Issues; SectorBased Trainers. LWATI: A Journal of Contemporary Research, 16(1), 24-41.

Komba, C. S \& Mwandaji, M (2016) Reflections on the implementation of competency-based the curriculum in Tanzanian secondary schools. Journal of Education and Learning 4 (2),73-80

Kupiainen, S., Hautamäki, J., \& Rantanen, P. (2008). EU pre-pilot on learning to learn. Report on the compiled data 2008-1190/001-001 TRATRINDC.

Lai, E. R., \& Viering, M. (2012). Assessing 21st Century Skills: Integrating Research Findings. Vancouver, B.C.: National Council on Measurement in Education.

Lukindo, J. J. (2016). Exploring Competence-Based Education (CBE) in Rural Secondary Schools in Tanzania: English Language Teachers' Conceptions and Experiences. Journal of Education and Practice, 7(29), 62-67

Makunja, G. (2016). Challenges Facing Teachers in Implementing Competence-Based curriculum in Tanzania: The Case of Community Secondary Schools in Morogoro Municipality. International Journal of Education and Social Science, 3(5), 30-37.

Mulenga, I. M. \& Kabombwe, Y. M. (2019). Competency-Based Curriculum for Zambian Primary and Secondary Schools: Learning from Theory and Other Countries in the World. International Journal of Education and Research. 7 (2), 117-130.

Musilekwa, S. \& Mulenga, I. M. (2019). Development of Social Studies Learners' Textbooks for Secondary Schools in Zambia. Journal of Education and Practice. 10 (6), 99108.

Nambela, C. (2016). An Evaluation of the Effectiveness of the Revised 2013 Curriculum on the Provision of Quality Secondary Education in Selected Schools in Kitwe District, Zambia. MEd Dissertation. The University of Zambia.

Ndihokubwayo, K., \& Habiyaremye, H. T. (2018). Why did Rwanda shift from knowledge to competence-based curriculum? Syllabuses and textbooks point of view. African Research Review, 12(3), 38-48.

Ngware, M. W., Oketch, M., \& Mutisya, M. (2014). Does teaching style explain differences in learner achievement in low and high performing schools in Kenya? International Journal of Educational Development, 36, 3-12.

Paulo, A. (2014). Pre-service teachers' preparedness to implement competence- the based curriculum in secondary schools in Tanzania. International Journal of Education and Research, 2(7), 219-230.

Pellegrino, J.W., \& Hilton, M.L (2012). Education for Life and Work: Developing Transferable Knowledge and Skills in the 21st Century. National Research Council. Washington, D.C., The National Academies Press

Partnership for 21st Century Skills (2009). P21 framework definitions. Retrieved from http://www.p21.org/storage/documents/P21_Fra mework_Definitions.pdf

Pepper, D. (2011) Assessing key competencies across the curriculum - and Europe. European Journal of Education, 46(3), 335-353.

Rychen D.S. \& Salganik, L.H. (Eds.). (2003). Key Competencies for a Successful Life and a Well-Functioning Society. Göttingen, Germany: Hogrefe \& Huber

Sossion, W. (2017). Teacher preparedness for the implementation of the competency-based the curriculum in preprimary and lower primary grades in Kenya. Nairobi; Kenya National Union of Teachers.

Swaffield, S. (2011) Getting to the heart of authentic Assessment for Learning, Assessment in Education. Principles, Policy \& Practice, 18:4, 433- 449

104| This work is licensed under a Creative Commons Attribution 4.0 International License. 
Takayama, K., Waldow, F., \& Sung, Y. K. (2013). Finland has it all? Examining the media accentuation of 'Finnish education' in Australia, Germany, and South Korea. Research in Comparative and International Education, 8(3), 307-325.

Voogt, J., \& Roblin, N. P. (2012). A comparative analysis of international frameworks for $21^{\text {st }}$ century competences: Implications for national curriculum policies. Journal of Curriculum Studies, 44 (3), 299-321.

Vainikainen, M.-P. (2014). Finnish primary school pupils' performance in learning to learn assessment: A longitudinal perspective on educational equity. The University of Helsinki, Department of Teacher Education Research Report 360. Helsinki: Unigrafia.

Vainikainen, M. P., Thuneberg, H., Marjanen, J., Hautamäki, J., Kupiainen, S., \& Hotulainen, R. (2017). How do Finns know? Educational monitoring without inspection and standardsetting. In Blömeke, S. \& Gustafsson, J. (Eds.), Standard Setting in Education: The Nordic Countries in an International Perspective (pp. 243-259). Springer International Publishing

Wanzala, O. (2018, July 22). Questions raised on teachers' readiness for the new curriculum. Daily Nation.

https://nation.africa/kenya/news/questionsraised-on-teachers-readiness-for-newcurriculum-69742

Wiliam, D. (2011). Embedded formative assessment. Bloomington, IN Solution Tree Press. https://www.bookdepository.com/EmbeddedFormative-Assessment.Wiliam/978193 